\title{
¿Es posible la justicia urbana en Chile? Análisis a la nueva institucionalidad en materia de mitigaciones y aportes al espacio público
}

\author{
Is urban justice possible in Chile? Analysis to the new institutionally in matters of mitigations and \\ contributions to public space
}

\section{A justiça urbana possível no Chile? Análise à nova institucionalidade em questões de mitigação e contribuição para o espaço público}

Christian Quinteros Flores. Ph.D(c). en Ordenamiento Territorial y Desarrollo Sostenible. cquinterosflores@gmail.com

(iD) https://orcid.org/0000-0002-6145-9347

Universidad Tecnológica de Chile INACAP. Chile.

Recibido: Julio 11 de 2017

Aceptado: Agosto 23 de 2018

Publicado: Diciembre de 2018

\section{RESUMEN}

La Gobernanza, como nuevo enfoque comprensivo de las dinámicas territoriales, exige identificar asimetrías de información y de poder que existen entre sus actores. En Chile, conflictos territoriales derivan de un neoliberalismo invasivo del suelo, sumado a procesos planificativos sin participación vinculante de la ciudadanía. Este trabajo revisa la Ley № 20.958 , identificando los actores que en ella intervienen, su vinculación con procesos de participación ciudadana que pretenden valorar los territorios locales y sus patrimonios. Se concluye que el criterio determinante de inclusión/exclusión social en la construcción de ciudad es la rentabilidad económica, subordinando las dimensiones de sostenibilidad social.

Palabras Clave: Gobernanza; justicia urbana; participación ciudadana; sostenibilidad social.

\begin{abstract}
Governance, as a new comprehensive approach to territorial dynamics, requires identifying asymmetries of information and power that exist among its actors. In Chile, territorial conflicts derive from an invasive neoliberalism of the soil, added to planning processes without the binding participation of citizens. This work reviews Law No. 20,958, identifying the actors involved in it, its link with processes of citizen participation that seek to assess local territories and their assets. It is concluded that the determining criterion of social inclusion/exclusion in the construction of a city is economic profitability, subordinating the dimensions of social sustainability.
\end{abstract}

Keywords: Governance; urban justice; citizen participation; social sustainability.

\section{RESUMO}

A governança como uma nova abordagem abrangente da dinâmica territorial requer a identificação de assimetrias de informação e poder que existem entre seus atores. No Chile, os conflitos territoriais derivam de um neoliberalismo invasivo do solo, associado a processos de planejamento sem a participação obrigatória dos cidadãos. Este trabalho revisa a Lei no 20.958 , identificando os atores envolvidos, sua conexão com processos de participação cidadã que visam avaliar os territórios locais e seus ativos. Conclui-se que o critério determinante de inclusão / exclusão social na construção de uma cidade é a rentabilidade econômica, subordinando as dimensões da sustentabilidade social.

Palavras-chave: Governança; justiça urbana; participação do cidadão; sustentabilidade social. público. Procesos Urbanos 5:49-57. DOI: https://doi.org/10.21892/2422085X.409 


\section{Introducción}

Los conflictos territoriales se generan, la mayoría de las veces, por competencias entre los actores actuales o potenciales de un territorio, y del uso racional de ciertos bienes públicos. En efecto, el territorio y su forma de planificación pasan a ser hoy un bien público, donde un proceso, que tradicionalmente fue técnico, hoy se ha transformado en un problema político. Las comunidades están cansadas de no ser consultadas en materia de crecimiento o de extensión urbanística. Los instrumentos de participación ciudadana en materia de planificación territorial se circunscriben en Chile a lo dispuesto en la Ordenanza General de Urbanismo y Construcción o lo establecido en las propias ordenanzas municipales de participación ciudadana, con mecanismos como audiencias públicas o plebiscitos comunales que escasamente son utilizados por la comunidad $y$, menos aún, son utilizados en materia de ordenamiento territorial. La Ley analizada reconoce la necesidad de introducir por la fuerza medidas compensatorias por parte de inversionistas, cuando quieren desarrollar proyectos que impacten en las condiciones de movilidad en un determinado territorio. Sin embargo, como se verá, estas nuevas disposiciones carecen también de formas de participación de la comunidad, dejando una vez más a los tecnócratas de Estado y de los municipios, las resoluciones de medidas que permitan niveles aceptables de justicia urbana. La Justicia Urbana

La justicia urbana, es un concepto incipiente relacionado con el enfoque de justicia ambiental y perfectamente podría inscribirse dentro de los objetivos de la agenda de desarrollo sostenible 2030 de las Naciones Unidas. Es así como el objetivo 11 de esta convención, busca que las ciudades y los asentamientos humanos sean "inclusivos, seguros, resilientes y sostenibles". La planificación de los espacios públicos en cualquiera de sus niveles debe construir ciudades de oportunidades, con acceso a servicios básicos, energía, vivienda, transporte y más facilidades para todos. Según el Informe 2017 de la ONU, sobre avances de la Agenda de Desarrollo Sostenible 2030, en los últimos decenios el mundo ha experimentado un crecimiento urbano sin precedentes. En 2015, cerca de 4.000 millones de personas (el $54 \%$ de la población mundial) vivía en ciudades y, según las proyecciones, ese número aumentará hasta aproximadamente 5.000 millones de personas para 2030. La rápida urbanización conlleva enormes dificultades, como el creciente número de habitantes de barrios marginales, el incremento de la contaminación atmosférica, la insuficiencia de los servicios básicos y la infraestructura, y el crecimiento urbano incontrolado y no planificado, que también aumentan la vulnerabilidad de las ciudades a los desastres. Se necesita mejorar la planificación y la gestión urbanas para que los espacios urbanos del mundo sean más inclusivos. En mayo de 2017, 149 países estaban formulando políticas urbanas a escala nacional, incluido Chile (Informe de Agenda de Desarrollo Sostenible, 2017).

Por otra parte, el objetivo $\mathrm{N}^{\circ} 16$ de la Agenda, busca promover sociedades justas, pacíficas e inclusivas. Este objetivo se centra en la promoción de un acceso universal a la justicia y la construcción de instituciones responsables y eficaces a todos los niveles (ONU, Agenda de Desarrollo Sostenible 2030, 2017). En este aspecto también se incluyen los crecientes problemas de conflictos socioambientales, y conflictos comunitarios en general, que derivan del uso inadecuado y antidemocrático del espacio territorial local, y a las nuevas institucionalidades que se adopten para nuevos relacionamientos comunitarios.

Por otro lado, el desarrollo se enfrenta a un proceso de capitalismo desregulado que, como señalan algunos autores, encuentra a un Estado-Nación débil, con pérdida de soberanía y con poder compartido. "En torno a ese choque entre globalización capitalista e identidad propia, se construye la dinámica del Estado, una dinámica caracterizada por la crisis del Estado-Nación y la emergencia del Estado-Red" (Castells, 2003, p.7). Según Castells, en tanto que la globalización se ha expresado básicamente como un instrumento de articulación de mercados capitalistas, el criterio determinante de inclusión o exclusión en este proceso es la rentabilidad. Sus otras dimensiones - cultura, ciencia y tecnología- son subordinadas a la racionalidad económica.

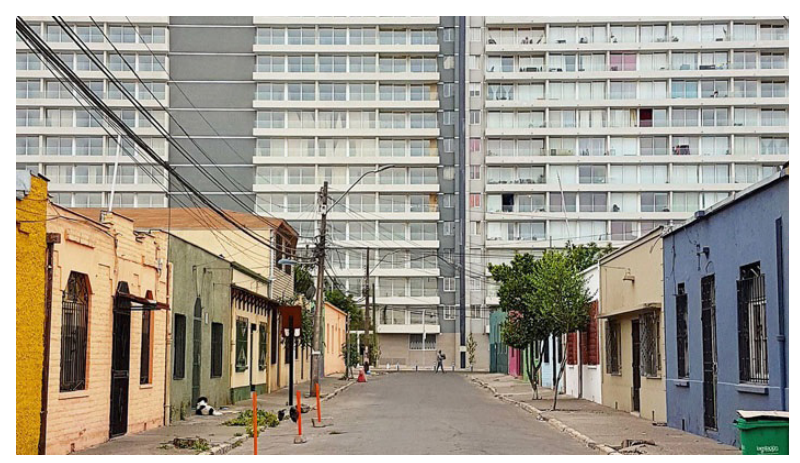

Figura 1. Guetos Verticales en comuna de Estación Central, Región Metropolitana.

Fuente: Diario La Nación, 2017.

Según Peck, el posicionamiento de las reformas neoliberales y su repercusión a través de escalas diferentes de gobierno y de gobiernos, varía de forma significativa según el caso. Según este autor, no deberíamos esperar una sola versión del neoliberalismo que se repita caso tras caso. Se puede afirmar, como patrón general, la existencia de una escala que supera al Estado, que sería la escala transnacional. A menudo vemos la existencia de un poder supranacional sin responsabilidad, por ejemplo, el poder ejercido por el Banco Mundial o el FMI, sin una carga de responsabilidad electoral. En efecto, los Estados-Nación en Latinoamérica establecen relaciones con estas instancias para acceder a recursos, con la condición de desarrollar programas de desarrollo o de ajustes económicos. Sin embargo, los efectos o consecuencias de esos ajustes son solo responsabilidad del Estado-Nación que los impulsó, descomprometiendo a los verdaderos gestores de esos cambios, sometiendo a los Estados a un juego político, donde ellos serán los únicos responsables de las decisiones de política pública. Por otro lado, en contraste se tiene en una escala local, gobiernos de ciudades que a menudo tienen responsabilidad pero no tienen poder. Se espera de ellos que mantengan los servicios para los residentes locales, son responsables por el clima económico de la ciudad y muchas otras cosas. Mientras muchas veces carecen de esta capacidad proveer eficientemente dichos servicios, de proveer crecimiento en una región particular, etc. Así que tenemos el caso que a las administraciones de ciudades se les carga demasiada responsabilidad, dadas sus capacidades limitadas, mientras en los niveles más altos vemos poder sin responsabilidad política (Peck, 2016). Claramente, se deja a los gobiernos locales el peso de la decisión en materia de planificación, mientras que, a nivel superior, las responsabilidades y costos políticos se diluyen.

Para este autor existen razones políticas para empujar hacia mayores grados de autonomía a una escala local. El gobierno local puede reflejar los intereses y necesidades de las poblaciones locales. Sin embargo, cuando se otorga autonomía 
sin la capacidad suficiente para implementar impuestos, para promulgar programas, etc., a menudo puede producirse una simple devolución, en términos de disciplina y austeridad. Descargar riesgos y responsabilidades a las escalas locales, se convierte en una estrategia común de las administraciones neoliberales a escala nacional. Es una forma de aplazar costos y riesgos de la reestructuración económica hacia las escalas más bajas de gobierno, en vez de su empoderamiento.

\section{El Desarrollo frente a Nuevos Lenguajes de Identidades y Valoración}

El proceso de la globalización, para el mismo Castells, ha reformulado el concepto de Identidad. Según este autor la Identidad, es el proceso por el cual los actores sociales construyen el sentido de su acción atendiendo a un atributo cultural (o conjunto articulado de atributos culturales) al que se da prioridad sobre otras fuentes posibles de sentido de la acción. El reforzamiento de las identidades culturales es el principio básico de organización social, seguridad personal y movilización política. De esta manera, los casos de movimientos sociales identitarios en el mundo plantean un rechazo explícito de la globalización y una denuncia del Estado, convertido en rehén de los flujos globales (Castells, 2003). Los territorios asumen nuevas formas para contrarrestar este poder del capitalismo. Una de ellas es la noción de valoración del patrimonio local y de todo aquello que confiera identidad y memoria a lo local.

Según Joan Martínez Alier, valorar no siempre significa atribuir un valor monetario. "Todo necio confunde valor y precio." La economía ecológica descansa más bien en la noción de inconmensurabilidad de valores. Hay muchos valores distintos. Valorar es dar importancia a algo o a alguien, y no siempre en dinero. No hay una unidad común de medida. Eso separa la economía ecológica de la convencional. Por ejemplo, en un conflicto socio ambiental se puede hablar de:

- Compensación monetaria de los daños sufridos por una de las partes.

- Derechos territoriales indígenas que se ejercen directamente, o, tras apelar a la Convención 169 de la OIT, que exige consentimiento previo informado, derecho a consulta con poder de veto.

- Existencia de ríos, lagos o cerros sagrados.

- Existencia de restos arqueológicos o paleontológicos que deben ser preservados.

- Valores ecológicos únicos, paisajes sin parangón, especies endémicas en peligro. (Martínez, 2015).

Con todo, América Latina está integrada en la nueva economía global, pero de forma desigual y tal vez insostenible, con altos costos sociales y económicos en la transición, y con amplios sectores sociales y territorios excluidos estructuralmente de ese proceso de modernización e integración económica. EI desarrollo desigual territorial se ha acentuado y la concentración de población y recursos en las grandes áreas metropolitanas sigue creciendo, suscitando tensiones sociales y deterioro medioambiental por falta de control y planeamiento de este proceso de urbanización acelerada (Castells, 2003).

En presencia de grupos sociales heterogéneos surgen también lenguajes de valoración, como respuesta natural a esta globalización y su neoliberalismo avasallador y a la pasividad casi expectante del Estado-Nación frente al problema de la urbanización acelerada. Una pregunta que cuestiona los tradicionales métodos de planificación en esta materia pudiera ser: ¿Quién tiene el poder de imponer una decisión? Y ¿quién tiene el de imponer el método de decisión? La ecología política estudia los conflictos socioambientales, por la extracción de materiales y energía, por el transporte, por la contaminación. Al mismo tiempo, el término designa un amplio movimiento social y político por la Justicia Ambiental, que es más fuerte en América Latina que en otros continentes. Este movimiento lucha, sin apoyo de partidos políticos, contra las injusticias ambientales en ámbitos locales, nacionales, regionales y globales.

El concepto de Justicia Ambiental se comienza a utilizar en la década de los 80, a partir de respuestas comunitarias frente a la globalización y a sus efectos nocivos al ambiente. Sin embargo, han existido otros movimientos sociales que han dado cuenta de esta idea de fortalecer los territorios y patrimonios. A continuación, se presentan las distintas conceptualizaciones que ha tenido la preocupación con la Justicia Ambiental y que ha transitado desde la preocupación por aspectos de integración social y/o de contaminación ambiental, hasta de concientización por los derechos de los ciudadanos y ciudadanas a la ciudad (Tabla 1).

¿Cuándo nace el concepto de Justicia Ambiental? ¿En qué contexto emerge? De acuerdo con Anguelovski, este concepto proviene de Estados Unidos y surge entre finales de la década de los 70 y principios de los 80 , cuando la población negra de Warren County (North Carolina), al sur de Estados Unidos, salió a las calles para protestar contra los vertidos que varias empresas estaban haciendo en el municipio. Aunque estas empresas estaban violando las leyes y la población había denunciado la situación a los poderes públicos, las agencias de medio ambiente ignoraban los vertidos y las protestas. Ante esta situación, la población se manifestó en las calles denunciando la pasividad de las agencias y afirmando que, por el hecho de ser negros, no merecían que sus calles y jardines estuvieran llenos de contaminantes, poniendo en peligro su salud y la de sus hijos. En estos primeros años, la investigación se centra en lo que se denomina "Brown Environmental Justice", todo lo referente al impacto negativo de actividades, los conflictos vinculados a vertidos, contaminación, extracción de recursos naturales, etc. $Y$ es que, aunque el concepto de "Justicia Ambiental" se empezó a usar en Estados Unidos, estas dinámicas y movimientos similares ya existían en otras partes del mundo, como Latinoamérica, India o África. Normalmente, eran casos en zonas alejadas de estos países, relacionados con la extracción de recursos naturales por empresas transnacionales y los impactos negativos que causaban en las poblaciones indígenas (Anguelovski, 2015).

Pero, ¿existe una dimensión específicamente urbana del concepto de Justicia Ambiental que nos pudiera acercar a la noción de Justicia Urbana? Martínez Alier argumenta que la Justicia Ambiental está vinculada a procesos de metabolismo en la sociedad. Cuanto más necesita la sociedad producción de bienes para consumir, más recursos naturales se extraen, siempre con impactos negativos a las poblaciones vulnerables, en zonas alejadas, las fronteras extractivas. Esto favorece la extracción de recursos y a la vez los conflictos, porque siempre necesitamos más producción, siempre necesitamos extraer más. Pero cuando nos referimos específicamente a las ciudades, no solamente se puede acumular beneficio por la extracción de recursos, su transformación y su venta, sino a través de la valoración y revalorización del suelo. "En procesos de especulación tan fuerte sobre el territorio, de intervenciones urbanísticas y arquitectónicas que cambian totalmente un entorno y las pautas de la vida de la gente, sus referencias y mundo visual, se generan procesos de trauma. Esto anima a la gente a pensar que su patrimonio debe ser valorado. No solamente se pueden mejorar las condiciones de la vivienda 
Tabla 1. Enfoques.

\begin{tabular}{|c|c|}
\hline Concepto & Descriptor \\
\hline Justicia Ambiental & $\begin{array}{l}\text { Usado desde } 1982 \text { por el movimiento en EE.UU. contra la contaminación en barrios pobres con población afro-americana } \\
\text { o hispana (Bullard, 1990). }\end{array}$ \\
\hline Racismo Ambiental & Contaminación o destrucción de bienes comunes de minorías étnicas; se usa en EE.UU. \\
\hline Epidemiología Popular & $\begin{array}{l}\text { Estudio y denuncia de la incidencia de la contaminación en la salud pública, en barrios o territorios "sin doctor" } \\
\text { (Phil Brown, 1997). }\end{array}$ \\
\hline Zonas de Sacrificio & $\begin{array}{l}\text { Steve Lerner (2010) publica un libro con este título resumiendo investigaciones en el seno del movimiento de } \\
\text { justicia ambiental en EE.UU. }\end{array}$ \\
\hline Justicia Climática & $\begin{array}{l}\text { Hay emisiones de } \mathrm{CO}_{2} \text { necesarias y hay emisiones de lujo (Agarwal y Narain, 1991). Política de contracción y convergencia } \\
\text { de las emisiones. }\end{array}$ \\
\hline $\begin{array}{l}\text { Ecologismo de los pobres, } \\
\text { ecologismo popular }\end{array}$ & $\begin{array}{l}\text { Defensa de la naturaleza y los bienes comunes por poblaciones pobres o indígenas empobrecidas, motivado por la } \\
\text { necesidad de sobrevivencia. }\end{array}$ \\
\hline Soberanía Alimentaria & El derecho proclamado por la Vía Campesina a alimentarse de los productos campesinos en mercados locales. \\
\hline Soberanía Energética & El derecho a abastecerse de energías renovables controlada localmente, distribuida en el territorio. \\
\hline Justicia Hídrica & $\begin{array}{l}\text { La asignación equitativa del agua, contra del hecho de que "el agua corre hacia el poder". Alianza de grupos } \\
\text { latinoamericanos bajo este nombre (impulsada por Rutgerd Boelens). }\end{array}$ \\
\hline "Desertos Verdes" & Se usa en Brasil contra plantaciones de eucaliptos para fábricas de celulosa. \\
\hline $\begin{array}{l}\text { Las plantaciones no } \\
\text { son bosques }\end{array}$ & $\begin{array}{l}\text { Lema del Movimiento Mundial por los Bosques Tropicales (WRM) contra los monocultivos de árboles como } \\
\text { eucaliptos, pinos, etc. Propuesto por Carrere y Lohman (1996). }\end{array}$ \\
\hline Agrocombustibles & $\begin{array}{l}\text { La Vía Campesina usa este término para plantaciones para etanol o biodiésel, evitando la connotación favorable } \\
\text { de "biocombustibles". }\end{array}$ \\
\hline Conservación de semillas in situ & $\begin{array}{l}\text { Movimiento en defensa del derecho de los campesinos a reproducir y difundir sus semillas. Revista Biodiversidad, } \\
\text { dirigida por Carlos Vicente. "Sin maíz no hay país" se dice en México en el movimiento En Defensa del Maíz. }\end{array}$ \\
\hline "Paren de fumigar" & $\begin{array}{l}\text { Se usa en Argentina contra la fumigación con glifosato en plantaciones de soja, que atenta contra la salud } \\
\text { humana. }\end{array}$ \\
\hline La agricultura campesina enfría la tierra & $\begin{array}{l}\text { Lema de la Vía Campesina muy visible en } 2009 \text { en la Conferencia de las Partes (COP) de la Convención de las } \\
\text { NNUU sobre el Cambio Climático en Copenhague, recogido por el amplio movimiento agroecologista. }\end{array}$ \\
\hline Acaparamiento de tierras & $\begin{array}{l}\text { GRAIN introdujo en } 2008 \text { la expresión land grabbing para designar una nueva ola mundial de desalojos } \\
\text { campesinos por empresas transnacionales. }\end{array}$ \\
\hline Resource caps & $\begin{array}{l}\text { Introducida por la Resource Cap Coalition en Europa, propuesta de topes a la extracción de determinados } \\
\text { materiales. }\end{array}$ \\
\hline Ogonización, yasunización & $\begin{array}{l}\text { Dejar petróleo, carbón y gas bajo tierra, para evitar daños locales y al mismo tiempo luchar contra el cambio } \\
\text { climático. Propuesta de Oilwatch en 1997, nacida en Nigeria y Ecuador. Naomi Klein le llama blockadia. }\end{array}$ \\
\hline $\begin{array}{l}\text { Responsabilidad empresarial, } \\
\text { civil y penal }\end{array}$ & $\begin{array}{l}\text { Se propone, en contra de la responsabilidad social corporativa, una legislación y una práctica vigorosas que } \\
\text { incluyan una convención internacional contra el ecocidio. }\end{array}$ \\
\hline El agua vale más que el oro & Un lema del movimiento contra la megaminería, que está bien representado por OCMAL. \\
\hline Derechos de la Naturaleza & Incluidos en la Constitución de Ecuador de 2008, en su artículo n. 71. \\
\hline $\begin{array}{l}\text { Recuperadores o Recicladores } \\
\text { Urbanos }\end{array}$ & $\begin{array}{l}\text { Movimiento de recicladores urbanos de basura (catadores, cartoneros, pepenadores) de toda Latinoamérica, } \\
\text { con éxitos en Bogotá y otras ciudades. }\end{array}$ \\
\hline Critical Mass & Movimiento que defiende los derechos de los ciclistas en las ciudades (Carlsson, 2008). \\
\hline Agricultura Urbana & $\begin{array}{l}\text { En EE.UU. la llaman guerrilla food gardening, muy presente en ciudades latinoamericanas. Movimientos de } \\
\text { permacultura. }\end{array}$ \\
\hline Colonialismo o Imperialismo Tóxico & $\begin{array}{l}\text { Nombre dado a la exportación internacional ilegal de residuos tóxicos (desguace de barcos, residuos } \\
\text { electrónicos, etc.). Red BAN. }\end{array}$ \\
\hline Postdesarrollismo, Postextractivismo & $\begin{array}{l}\text { Dos crecientes movimientos presentes en América Latina desde los años } 1990 \text { (el primero) y los } 2000 \text { (el } \\
\text { segundo) (A. Escobar, 1995; G. Esteva, 1992; E. Gudynas, 2010; M. Svampa, 2013). }\end{array}$ \\
\hline $\begin{array}{l}\text { Buen Vivir, Sumak Kawsay y } \\
\text { otros términos análogos }\end{array}$ & Un objetivo distinto al desarrollo económico, que fue incluido en la Constitución de Ecuador de 2008. \\
\hline
\end{tabular}

Fuente: Joan Martínez Alier. Presentación realizada en el CIDECI, Universidad de la Tierra, San Cristóbal de las Casas (Chiapas), el 5 de noviembre de 2015. 
destruyendo un edificio y construyendo algo muy moderno" (Anguelovski, 2015). En este sentido, la urbanización acelerada muchas veces "rompe" con lo ya existente, sin reconocer los lenguajes de valoración cultural que subyacen o están presentes en las comunidades. El neoliberalismo avasallador, fundado en criterios rentabilistas o economicistas, exige a los Estados decisiones rápidas y eficientes, de acuerdo con sus intereses, aunque esto suponga desconocer la opinión de la comunidad.

Según Anguelovski, el rol de los activistas en los barrios, para impulsar mejoras en el acceso a estos Bienes Ambientales es distinto y varía en diferentes momentos. Hay un momento inicial en el que la gente dice "basta ya". Basta ya de exclusión social, racial, de poderes públicos que no intervienen cuando hay una violación ambiental, de la calidad del aire, del agua, de contaminantes en el suelo. Gente que dice basta de violencia en los espacios verdes que, además, están sucios, que no sirven para usos recreativos; un sentimiento muy fuerte de exasperación que empieza cuando el barrio está en una situación extrema de deterioro.

Específicamente en Chile, Manuel Castells señala que los gobiernos de la "Concertación" desde los inicios de los años 90, negociaron con los poderes fácticos el mantener sus privilegios y derecho de veto y buscaron una nueva legitimidad basada en la continuidad de la legitimidad del mercado. Agregaron un "correctivo": el Estado deja de ser instrumento de exclusión para ser instrumento de integración, mediante políticas sociales de redistribución y mediante la creación de un sistema de relaciones industriales y organización institucional de la relación Sociedad-Estado (Castells, 2003).

Claramente, la necesidad de impulsar leyes y normas como las que revisaremos en este artículo tienen estrecha relación con esta última idea. En efecto, los gobiernos nacionales y locales deben establecer relaciones sociales que permitan la inversión y la productividad, aunque muchas veces esas actividades destruyan o deterioren el medioambiente, o requieran hacer ajustes de última hora a los instrumentos de planificación territorial frente a las nuevas exigencias y urgencias de los inversionistas. En este momento la institucionalidad introduce nuevas normas o reglas del juego que permitan invertir, aunque sigan estando controlados por los burócratas o tecnócratas, y desconozcan la participación de la ciudadanía en estas nuevas definiciones, aunque sea esta última la que vea afectada directamente su calidad de vida.

\section{Antecedentes de la Ley № 20.958}

El proyecto de ley, que posteriormente da cuenta de la Ley No 20.958, fue presentado a la Cámara de Diputados por el entonces gobierno de la "Nueva Mayoría", en el año 2012, y se propuso "rescatar el principio original de la legislación urbanística chilena, en cuanto a que todos los proyectos de construcción en los que van a habitar personas colaboren en la conformación de ciudades equilibradas, en las cuales no solo los recintos privados sean los adecuados, sino también los espacios públicos, los lugares donde transcurre gran parte de la vida de las personas, espacios colectivos que dan sentido a la idea de "civitas", que hace que una ciudad sea más que una simple aglomeración de construcciones, y que, a su vez, sus habitantes se conviertan en "ciudadanos" (Bachelet, 2012). Según esta moción legislativa, la necesidad de espacio público debe ser siempre proporcional al número de personas que habitan un determinado sector de la ciudad, en las distintas formas de habitar las edificaciones, no solo en el caso de las viviendas. Es decir, contar con un espacio público de calidad es un requisito tanto frente a las casas, como los departamentos, las oficinas o los centros comerciales.

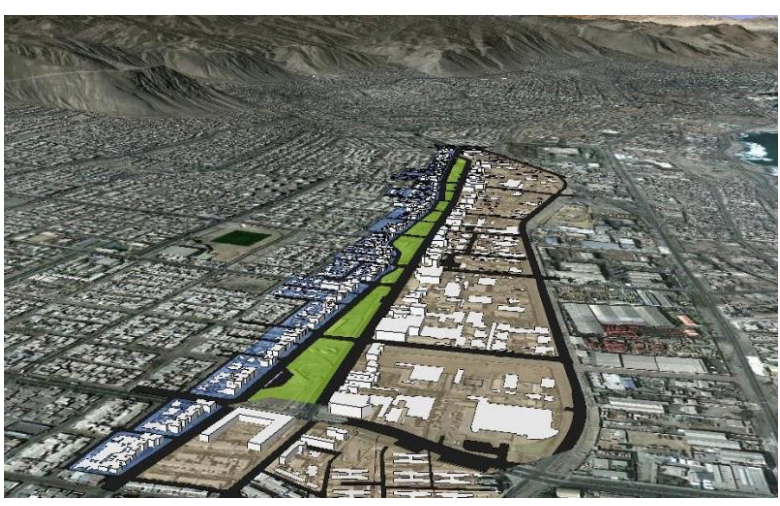

Figura 2. Proyecto de Ampliación de Ciclovías en Comuna de Antofagasta, Región de Antofagasta.

Fuente: Diario El Nortero, 2011.

Es así como, después de cuatro años de debate y tramitación legislativa, el 15 de octubre de 2016 se publicó en el Diario Oficial la Ley $\mathrm{N}^{\circ} 20.958$ de aportes al espacio público. Esta nueva ley, modificó diversas disposiciones de la Ley General de Urbanismo y Construcciones y otras leyes, y persiguió que los nuevos desarrollos inmobiliarios resuelvan adecuadamente los impactos que generan sobre la ciudad (no los déficits pre existentes), Esto tiene como fin que las mitigaciones se hagan cargo de las externalidades negativas que puede producir el nuevo proyecto, como la congestión o en el sistema de movilidad local. Para ello, se cobraría una mitigación por dos tipos de conceptos: las mitigaciones directas y los aportes al espacio público, siguiendo los principios de universalidad, proporcionalidad y predictibilidad. Para ello, establece dos herramientas centrales:

Las "Mitigaciones Directas", a través de las cuales los proyectos inmobiliarios (públicos y privados) se hacen cargo de los impactos que generan en la movilidad local.

Los "Aportes al Espacio Público", mecanismo alternativo para que los proyectos inmobiliarios que densifican puedan cumplir la obligación de ceder terrenos.

La Ley 20958 introduce modificaciones a la Ley General de Urbanismo y Construcciones y a la Ley de Municipalidades, estableciéndose que, a través de planos de detalle subordinados a los planes reguladores comunales, seccionales o intercomunales, podrán fijarse con exactitud el diseño y características de los espacios públicos, los límites de las distintas zonas o áreas del plan y, en el caso de los planes reguladores comunales y seccionales, el agrupamiento de edificios y las características arquitectónicas de los proyectos a realizarse en sectores vinculados con monumentos nacionales, en inmuebles o zonas de conservación histórica o en sectores en que el plan regulador exija la adopción de una determinada morfología o un particular estilo arquitectónico de fachadas. Estos planos de detalle serán elaborados y aprobados, con los siguientes cambios:

a) Deberán contener una breve memoria y disposiciones reglamentarias.

b) Se deberá realizar una o más audiencias públicas en los barrios o sectores afectados para exponer la propuesta de plan de detalle a la comunidad, en la forma establecida en la ordenanza de participación ciudadana de la respectiva municipalidad.

c) Antes de su aprobación, se expondrán a la comunidad por un plazo de treinta días, vencido el cual los interesados podrán

Procesos 53 
formular observaciones escritas y fundadas hasta por otros treinta días, aplicándoseles lo previsto en el Artículo 43.

Los Principios aplicables a las mitigaciones y aportes que introduce la Ley son los siguientes:

a) Universalidad: Todos los proyectos inmobiliarios públicos y privados deberán mitigar y/o aportar conforme a las reglas del presente Título.

b) Proporcionalidad: Las mitigaciones deberán ser equivalentes a las externalidades efectivamente generadas por el proyecto, y no se harán cargo de los déficits históricos de infraestructura. Los aportes se ajustarán a la densidad y al destino del proyecto.

c) Predictibilidad: Las mitigaciones y aportes se calcularán según métodos objetivos y con base en procedimientos y plazos predefinidos y estandarizados. La Administración velará porque puedan conocerse en forma oportuna las obras y aportes que se exigirán.

En esta Ley se entenderá por Crecimiento Urbano por Extensión el proceso que incorpora nuevo suelo urbanizado a consecuencia de un loteo; y por Crecimiento Urbano por Densificación, el proceso que incrementa la intensidad de ocupación del suelo, sea como consecuencia del aumento de sus habitantes, ocupantes o edificación. Lo anterior se aplicará a los proyectos ubicados dentro de los límites urbanos y a los situados fuera de ellos, y autorizados conforme lo dispuesto en esta ley.

Asimismo, los proyectos que conlleven crecimiento urbano por extensión o por densificación, y ocasionen impactos relevantes sobre la movilidad local, deberán ser mitigados a través de la ejecución de medidas relacionadas con la gestión e infraestructura del transporte público y privado, y los modos no motorizados y sus servicios conexos, en el entendido de que esto incluye soluciones como las siguientes: pistas exclusivas para buses, terminales, paraderos, semaforización, señalización, habilitación de ciclo vías y mejoramientos o adecuaciones a la vialidad. Estas medidas de mitigación considerarán los impactos del proyecto sobre el sistema de movilidad local, dentro de su área de influencia, y propenderán a que, tras su puesta en operación, aquel mantenga sus estándares de servicio en un nivel semejante al existente, considerando las características de la zona en que se emplaza y resguardando la circulación segura de peatones y medios de transporte, las condiciones de accesibilidad del proyecto, su interacción con el sistema de movilidad y su inserción armónica con el entorno urbano.

El área de influencia del nuevo proyecto se definirá a partir de la dispersión de los flujos vehiculares o peatonales inducidos por el proyecto en la vialidad circundante, considerada desde los accesos. Para este efecto, se considerarán todas las intersecciones, salvo aquellas que incluyan calles sin salida, pasajes o calles peatonales. Excepcionalmente, el área podrá extenderse hasta la duodécima intersección, tratándose de dos o más proyectos cercanos en su localización que presenten, en forma conjunta, un informe de mitigación de impacto vial (en adelante "informe de mitigación"), o de proyectos individuales que induzcan mil o más viajes en transporte privado o tres mil o más viajes totales por hora, al menos en un período del día. En el caso de los proyectos de loteos, se considerará un área de influencia comprendida desde los accesos y, como máximo, hasta la vigésima intersección en que se realiza una dispersión del flujo vehicular o peatonal, conforme lo establezca el reglamento.
El contenido del Informe de Mitigación de Movilidad Urbana El Informe de Mitigación se elaborará y evaluará conforme al procedimiento y a la metodología que fije el reglamento expedido por decreto del Ministerio de Transportes y Telecomunicaciones, suscrito por el Ministro de Vivienda y Urbanismo, y aplicará los principios de celeridad, economía procedimental y no formalización. Atendiendo a las características y al impacto que pueda producir el proyecto en el área de influencia, el reglamento:

a) Establecerá categorías diferenciadas de informes, en función de los flujos vehiculares y peatonales inducidos por el proyecto, $y$, fundadamente, podrá reducir, para una o todas las categorías, los plazos máximos contemplados.

b) Fijará las condiciones para que dos o más proyectos que sean cercanos en su localización puedan realizar un informe de mitigación conjunto, a propuesta de los interesados o de la autoridad respectiva.

c) Determinará en qué categorías los informes podrán ser confeccionados por los proyectistas, y deberán ser presentados, a través del sistema electrónico, ante la unidad municipal encargada de la función de tránsito y transporte públicos (en adelante, Dirección de Tránsito y Transporte Públicos Municipal); a través del mismo sistema, ante la Secretaría Regional Ministerial de Transportes y Telecomunicaciones, y elaborados por un consultor inscrito en el registro que, para estos efectos, llevará la Subsecretaría de Transportes.

d) Definirá los proyectos en los que no se requerirá elaborar Informes de Mitigación por no producir alteraciones significativas en el estándar de servicio del sistema de movilidad local.

e) Detallará el contenido del Informe de Mitigación del proyecto, que deberá incluir sus características y área de influencia y la justificación de las medidas de mitigación propuestas, representadas gráficamente, todo ello de conformidad a la metodología definida por el reglamento.

Las medidas propuestas en el informe, en conjunto con la ejecución de las consideradas en el plan de inversiones en infraestructura de movilidad y espacio público, deberán mitigar los efectos del proyecto sobre el sistema de movilidad dentro del área de influencia, para que sus estándares de servicio tengan un nivel semejante al existente, de acuerdo con las características de la zona en que se inserta. El proyecto no podrá recepcionarse si no se han materializado las obras del Plan de Inversiones en infraestructura de movilidad y espacio público, cuya ejecución hubiere previsto el informe. La resolución que apruebe el Informe de Mitigación deberá consignar las características del proyecto, las medidas de mitigación aprobadas, la posibilidad de considerar etapas con mitigaciones parciales y la de garantizar las obras a ejecutar.

Las Direcciones de Obras Municipales no podrán cursar la recepción definitiva del proyecto, sin que el interesado acredite la ejecución de las medidas contenidas en la resolución que apruebe el informe de mitigación o el otorgamiento de una caución que la garantice cuando la resolución lo autorice. En caso de que dicha resolución haya considerado etapas con mitigaciones parciales, la recepción de cada etapa requerirá de la ejecución conforme de sus respectivas mitigaciones o del otorgamiento de la caución que la garantice si así se autorizó. El certificado de recepción definitiva deberá consignar las medidas de mitigación que hubieren sido garantizadas 


\section{De los Aportes al Espacio Público}

Los proyectos que conlleven crecimiento urbano por densificación deberán dar cumplimiento a través de un aporte equivalente al avalúo fiscal del porcentaje de terreno a ceder a la municipalidad respectiva, para las finalidades y en la forma que se establecen. Los aportes se ajustarán a la densidad y al destino del proyecto, en la forma que disponga la Ordenanza General.

Respecto del rol de los municipios, en esta medida de mitigación cada municipio elaborará un plan comunal de inversiones en infraestructura de movilidad y espacio público, que contendrá una cartera de proyectos, obras y medidas incluidas en los instrumentos de planificación territorial existentes o asociadas a estos, debidamente priorizadas, para mejorar sus condiciones de conectividad, accesibilidad, operación y movilidad, así como la calidad de sus espacios públicos y la cohesión social y sustentabilidad urbanas. Para estos efectos, el municipio contará con la asistencia técnica de las secretarías regionales ministeriales de Vivienda y Urbanismo y de Transportes y Telecomunicaciones, y del Programa de Vialidad y Transporte Urbano del Ministerio de Transportes y Telecomunicaciones. El plan deberá someterse a la aprobación del concejo municipal respectivo. Una vez aprobado, será promulgado por el alcalde, quien remitirá copia al gobierno regional. Las municipalidades podrán solicitar al gobierno regional la elaboración de estos planes o también incluirlos en la formulación o actualización del plan comunal de desarrollo a que se refiere el Artículo 6 de la ley $N^{\circ} 18.695$, orgánica constitucional de Municipalidades (Ley № 18.695).
Los planes comunales e intercomunales de inversiones en infraestructura de movilidad y espacio público, deberán actualizarse periódicamente en un plazo no mayor a diez años, y cada vez que se apruebe un nuevo instrumento de planificación comunal o intercomunal, siguiendo el mismo procedimiento señalado anteriormente.

Los aportes serán recaudados por el municipio respectivo, que deberá mantenerlos en una cuenta especial y separada del resto del presupuesto municipal. Los aportes estarán destinados única y exclusivamente a los siguientes fines:

a) Ejecución de obras identificadas en los planes comunales e intercomunales de inversiones en infraestructura de movilidad y espacio público, incluida la construcción de las nuevas áreas verdes o espacios públicos allí indicados.

b) Pago de expropiaciones que sean necesarias para la materialización de dichas obras.

c) Actualización de los planes de inversiones en infraestructura de movilidad y espacio público; desarrollo de los instrumentos de planificación que sean necesarios para su ejecución y elaboración de los proyectos de las obras.

d) Gastos de administración e inspección, incluidos aquellos en personal, hasta por el $10 \%$ de los fondos recaudados.

Cuando los planes reguladores intercomunales establezcan nuevas áreas urbanas o de extensión urbana podrán determinar condiciones adicionales de urbanización y equipamiento para el desarrollo de los proyectos que se emplacen en ellas, incluyendo

Tabla 2. Gobiernos Nacional y Sub nacionales involucrados en la Implementación de la Ley.

\begin{tabular}{|c|c|}
\hline Gobierno Nacional & Tarea \\
\hline $\begin{array}{l}\text { Ministerios de Vivienda } \\
\text { Telecomunicaciones }\end{array}$ & $\begin{array}{l}\text { La estimación de los flujos vehiculares y peatonales inducidos por el proyecto. Implementación de un } \\
\text { sistema electrónico. }\end{array}$ \\
\hline $\begin{array}{l}\text { Ministerio de Transportes y Telecomunicaciones, suscrito por el Ministro } \\
\text { de Vivienda y Urbanismo }\end{array}$ & $\begin{array}{l}\text { El Informe de Mitigación se elaborará y evaluará, conforme al procedimiento y a la metodología que fije } \\
\text { el reglamento expedido por decreto. }\end{array}$ \\
\hline $\begin{array}{l}\text { Ministerio de Transportes y Telecomunicaciones y de los respectivos } \\
\text { municipios }\end{array}$ & $\begin{array}{l}\text { Tener a disposición permanente del público, en los sitios electrónicos, los Informes de Mitigación que } \\
\text { se presenten y las resoluciones finales. }\end{array}$ \\
\hline Subsecretaría de Transportes & Creará y administrará un registro de consultores en Informes de Mitigación de impacto vial. \\
\hline Secretaría Regional Ministerial de Transportes y Telecomunicaciones & Indicará si el titular debe elaborar un Informe de Mitigación. \\
\hline $\begin{array}{l}\text { Secretaria Regional ministerial de Transportes y Telecomunicaciones o } \\
\text { el Director de Tránsito y Transporte Públicos Municipal }\end{array}$ & $\begin{array}{l}\text { Aprobar, observar o rechazar el Informe de Mitigación, mediante resolución fundada, previa consulta a } \\
\text { los demás órganos competentes. }\end{array}$ \\
\hline
\end{tabular}

Gobierno Regiona incluirlos en la formulación o actualización del Plan Comunal de Desarrollo a que se refiere el Artículo 6 de la Ley № 18.695 , orgánica constitucional de Municipalidades.

Elaborar y aprobar los planes de inversiones en infraestructura de movilidad y espacio público asociados al plan o a los planes reguladores metropolitanos o intercomunales existentes en la región, con consulta a las respectivas municipalidades.

\section{Gobierno Municipal}

Dirección de Tránsito y Transporte Público

Direcciones de Obras Municipales DOM

Secretaria Comunal de Planificación SECPLA

Concejo Municipal

Dirección de Finanzas

\section{Tarea}

Determinará en qué categorías los informes podrán ser confeccionados por los proyectistas, y deberán ser presentados a través del sistema electrónico.

No podrán cursar la recepción definitiva del proyecto, sin que el interesado acredite la ejecución de las medidas contenidas en la resolución.

Elaborar un plan comunal de inversiones en infraestructura de movilidad y espacio público, que contendrá una cartera de proyectos, obras y medidas incluidas en los instrumentos de planificación territorial existentes o asociadas a estos.

El plan deberá someterse a la aprobación del concejo municipal respectivo. Una vez aprobado, será promulgado por el alcalde, quien remitirá copia al Gobierno Regional.

Los aportes serán recaudados por el municipio respectivo, que deberá mantenerlos en una cuenta especial y separada del resto del presupuesto municipal.

Fuente: Elaboración propia 
la ejecución de obras de urbanización fuera del terreno en que se ubica el proyecto, la ejecución de obras o medidas en el sistema de movilidad urbana o que mejoren los espacios públicos, la inclusión de tipos de vivienda o usos de suelo en sus proyectos, la materialización o mejoramiento de equipamientos públicos u otras medidas que promuevan la integración social, todo lo cual se determinará de acuerdo con un estudio de impacto urbano y las reglas que establezca la Ordenanza

Los planes reguladores comunales podrán otorgar incentivos en las normas urbanísticas aplicadas en todo o parte de su territorio condicionados al desarrollo de espacios públicos o al mejoramiento de los ya existentes, a la materialización, reparación o mejoramiento de equipamientos públicos, a la instalación o incorporación de obras de arte en el espacio público o al cumplimiento de otras condiciones que induzcan o colaboren en el mejoramiento de los niveles de integración social urbana.

Como se ha visto, la Ley introduce medidas de mitigación urbana que beneficien a la comunidad que resida en un territorio donde se desarrolle un nuevo proyecto inmobiliario y que vea afectada sus condiciones de movilidad. Sin embargo, la institucionalidad observada en materia de participación ciudadana sobre los efectos de nuevos proyectos es más bien reducida y acotada a los organismos técnicos, tanto municipales como centralizados.

La participación ciudadana puede entenderse como la instancia donde las personas (entendidas como sujetos con capacidades, derechos y deberes) se involucran en el quehacer estatal, fortaleciendo la transparencia, la eficacia y eficiencia de los servicios y políticas públicas. En otras palabras, la participación ciudadana ocurre cuando los ciudadanos se involucran en la gestión pública, oportunidad que, en el caso de Chile, se concreta a través de los 4 procedimientos que establece nuestra Ley de Participación Ciudadana, como lo son el acceso a la información relevante, las consultas ciudadanas, las cuentas públicas participativas y los consejos de la sociedad civil (Ministerio de Vivienda y Urbanismo, 2018). En esta materia, las disposiciones transitorias de esta Ley establecen que los primeros planes comunales e intercomunales de inversiones en infraestructura de movilidad y espacio público que se elaboren en cada comuna o territorio intercomunal o metropolitano deberán, antes de iniciarse su proceso de aprobación, ser sometidos por la autoridad que los elabore a una consulta pública durante treinta días. Además, los ministerios de Transportes y Telecomunicaciones y de Vivienda y Urbanismo deberán publicar y someter a consulta pública, durante treinta días, el proyecto del reglamento a que se refiere el Artículo 171 de la Ley General de Urbanismo y Construcciones. No señala explícitamente ninguna instancia de participación ciudadana en la medida de mitigación, una vez que los interesados presentan los proyectos de inversión que afecten la movilidad dentro del territorio, lo que representa claramente una despotenciación de lo que entendemos por un sistema de Gobernanza. Claramente debe avanzarse en esta materia en nuevos proyectos que busquen estas medidas de mitigaciones.

\section{Conclusiones}

La definición de normas, que mitiguen las externalidades negativas de un proyecto, resulta claramente un avance en materia de desarrollo social, pero, en el caso revisado, no van la dirección de lo que establece un sistema robusto de gobernanza, donde la justicia urbana debiera ser un factor que permita reducir las nefastas asimetrías de poder, información y decisión. El rol de la comunidad sigue estando ausente en materia de protagonismo político. La definición de normas revisadas sigue un modelo tecnócrata y político al involucrar al Concejo Municipal, instancia eminentemente política, basada en un sistema representativo tradicional expuesto muchas veces a los intereses locales, partidistas y clientelistas.

Por otra parte, los gobiernos sub nacionales mantienen su sistema de tutelaje hacia los municipios locales, generando, como señalan Irarrázaval y Pérez, un sistema muy poco descentralizador de las decisiones (Irarrázaval y Pérez, 2008). Las Secretarias Regionales de los Ministerios siguen ejerciendo poder y control sobre las actividades del gobierno local y estos deben seguir reportando sus planes de desarrollo a las instancias regionales. Las modificaciones, incluso las que realiza al cuerpo legal analizado a las leyes de Urbanismo y Construcciones y a la Ley de Municipalidades, siguen en la misma línea, pese a las nuevas demandas por entregar mayor autonomía a los municipios.

Los procesos inmobiliarios privados siguen generando modificaciones obligadas a los instrumentos de planificación territorial, de una forma improvisada y poco sostenible, desestimando el verdadero potencial que significa un plan regulador comunal, que debiera diseñar estratégicamente el proceso de crecimiento de un determinado territorio. De esta manera, la introducción de nuevos proyectos inmobiliarios o de servicios somete, cada cierto tiempo, al municipio a la revisión del instrumento matriz de desarrollo, dejando a los técnicos locales en una posición extremadamente reactiva y pasiva frente al desarrollo.

Por último $-y$ lo que es más complejo a nuestro parecer-, este tipo de normas despotencia el camino hacia un modelo de gobernanza, como lo señalan Salazar y Pinto. Para estos autores, la Gobernabilidad es una tarea estatal que se define como la necesidad sistémica de mantener la sociedad civil disciplinada y sujeta bajo un estado de derecho. Por su parte, la Gobernanza se refiere "al poder o derecho de mantener a políticos tecnócratas y militares sujetos al control cívico y a la razón histórica de la ciudadanía. Poco a poco subrepticiamente los movimientos de la sociedad civil tienen a exigir proponer o construir un sistema político donde la gobernanza y no la mera gobernabilidad sea el componente legal de la política cotidiana" (Salazar y Pinto, 1999, pág. 18).

La gobernanza, en materia de planificación territorial, es una realidad irreversible. Los ciudadanos cada vez están más conscientes que las relaciones de igualdad o desigualdad política dependen en gran medida de las posiciones físicas o geográficas que los habitantes de un territorio tengan en él. Los tecnócratas locales y los políticos deben ir, progresivamente entonces, incorporando una institucionalidad que favorezca esta forma de gobierno compartido, como lo señala Castells.

La valoración de lo local, por parte de los tecnócratas protagonistas, sigue estando ausente, y continúan los mismos procedimientos participativos que someten estos nuevos proyectos a información en diarios locales, a celebración de audiencias públicas con escasa participación y a la utilización de lenguajes técnicos, que en nada contribuyen a democratizar estos procesos de restauración urbanística. El criterio determinante de inclusión o exclusión en este proceso es la rentabilidad. Sus otras dimensiones - cultura, ciencia y tecnología- son subordinadas a la racionalidad económica.

Estas medidas de mitigación si bien considerarán los impactos del proyecto sobre el sistema de movilidad local, dentro de su área de influencia, y propenderán a que, tras su puesta en operación, aquel mantenga sus estándares de servicio en un nivel semejante al existente, considerando las características de la zona en que se emplaza y resguardando la circulación segura de peatones y medios de transporte, las condiciones de accesibilidad del proyecto, no contribuyen a nuestro juicio a generar nuevos estándares de gobernanza. Una adecuada planificación territorial, con participación ciudadana, debe generar procesos urbanos debidamente priorizados, donde los vecinos puedan mejorar sus condiciones de conectividad, accesibilidad, operación y movilidad, así como la calidad de sus espacios públicos y la cohesión social y sustentabilidad urbana. 


\section{Referencias}

Bachelet, M. (2012) Mensaje de S.E. El Presidente de la República. 03 de agosto, 2012. Mensaje en Sesión 66. Legislatura 360. Primer Trámite Constitucional: Cámara de Diputados

Castells, M. (2003) Estado, Sociedad y Cultura en la globalización de América Latina con referencia a la especificidad chilena. Documento presentado al Foro de Altos Estudios Valparaíso

Anguelovsk, I. (2015). Entrevistador: Santiago Gorostiza La Justicia Ambiental urbana en la renovación de los barrios. Entrevista con Isabelle Anguelovsk. Revista Ecología Política Cuadernos de Debate Internacional. № 47

Martínez Alier, J.(2015). La ecología política y el movimiento global de justicia ambiental Presentación realizada en el CIDECI, Universidad de la Tierra, San Cristóbal de las Casas (Chiapas), el 5 de noviembre de 2015

LEY No 20.958 (2016). Norma que establece un Sistema de Mitigaciones y Aportes al Espacio Público. Ministerio de Vivienda y Urbanismo. Biblioteca del Congreso Nacional

Irarrázaval, I y Pérez, E. (2008) "Institucionalidad sub nacional y el problema de coordinación de competencias". Un Mejor Estado para Chile. Pág. 175-205

Ministerio de Vivienda y Urbanismo. MINVU (2018). Disponible en http://participacionciudadana.minvu.cl/consultas-ciudadanasvirtuales/consulta-p\%C3\%BAblica-sobre-propuestas-de-reglamentos-ley-n\%C2\%B0-20958-de, consultado el 10 de Junio de 2018

Salazar, G y Pinto, J. (1999) Historia Contemporánea de Chile I: Estado Legitimad y Ciudadanía Editorial LOM

Peck, J. (2015) Neoliberalismo variopinto y desafíos urbano-territoriales. Entrevista a Jamie Peck. Efectuada por Felipe Link. Documento de Trabajo № 8. Centro de Estudios de Conflicto y Cohesión Social (COES)

UN. (2017). Progresos en el logro de los Objetivos de Desarrollo Sostenible Informe del Secretario General. Período de sesiones de 201728 de julio de 2016 a 27 de julio de 2017. 